\title{
Long-Term Body Mass Index Variability, Weight Change Slope, and Risk of Cardiovascular Outcomes: 7-Year Prospective Study in Chinese Hypertensive Subjects
}

\author{
Zefeng Cai ${ }^{a}$ Weiqiang Wu ${ }^{b}$ Zekai Chen ${ }^{a}$ Wei Fang ${ }^{a}$ Weijian Li $^{a}$ \\ Guanzhi Chen $^{c}$ Zhichao Chen ${ }^{b}$ Shouling Wu ${ }^{d}$ Youren Chen ${ }^{b}$ \\ a Shantou University Medical College, Shantou, China; ${ }^{b}$ Department of Cardiology, Second Affiliated Hospital of \\ Shantou University Medical College, Shantou, China; ${ }^{C}$ China Medical University, Shenyang, China; ${ }^{d}$ Department of \\ Cardiology, Kailuan General Hospital, Tangshan, China
}

\section{Keywords}

Body mass index - Variability - Weight change slope .

Hypertension · Cardiovascular outcomes

\begin{abstract}
Background: The relationship between long-term body mass index (BMI) variability, weight change slope, and risk of cardiovascular outcomes in Chinese hypertensive patients has not been fully elucidated. Methods: A total of 20,737 patients with hypertension and three BMI measurements between 2006 and 2011 were included. Average real variability (ARV) was used to evaluate variability, and the subjects were divided into three groups: tertile 1 with BMI_ARV $\leq 0.86$; tertile 2 with $0.86<$ BMI_ARV $\leq 1.60$; and tertile 3 with BMI_ARV $>1.60$. Cox proportional-hazards models were used to analyze the risk of cardiovascular and cerebrovascular diseases (CVD) in each group. Results: There were 1,352 cases of CVD during an average follow-up of 6.62 years. The 7-year cumulative incidence rates of CVD, stroke, and myocardial infarction (MI) in tertile 3 were $7.53,6.13$, and $1.56 \%$, respectively. After adjustment for average $\mathrm{BMI}$, weight change slope, and other traditional risk factors, the hazard ratio $(\mathrm{HR})$ values for
\end{abstract}

karger@karger.com www.karger.com/ofa

Karger ${ }^{\prime \prime} \div$

BOPEN ACCESS
(C) 2021 The Author(s)

Published by S. Karger AG, Basel

This article is licensed under the Creative Commons AttributionNonCommercial-NoDerivatives 4.0 International License (CC BYNC-ND) (http://www.karger.com/Services/OpenAccessLicense) Usage and distribution for commercial purposes as well as any distribution of modified material requires written permission.
CVD, stroke, and $\mathrm{MI}$ in the highest tertile were 1.21 (95\% Cl 1.05-1.39), 1.21 (95\% Cl 1.04-1.38), and 1.20 (95\% Cl 0.881.62), respectively. Subgroup analysis showed that the HR values for CVD in tertile 3 were 1.71 (95\% Cl 1.06-2.75) and $0.98(95 \% \mathrm{Cl} 0.61-1.58)$ in the positive and the negative weight change subjects, respectively. Conclusions: Higher $\mathrm{BMI}$ variability was associated with increased risk of CVD in hypertensive subjects with weight gain but not in those with weight loss, independent of traditional cardiovascular risk factors.

(C) 2021 The Author(s) Published by S. Karger AG, Basel

\section{Introduction}

The prevalence of overweight and obesity among adults continues to increase. In 2015, the obese or overweight population reached 2.2 billion, accounting for $30.1 \%$ of the population worldwide [1]. The increasing prevalence of obesity has been associated with corre-

\section{Z. Cai and W. Wu contributed equally to this work.}


sponding increases in the prevalence of hypertension, diabetes, and cardiovascular and cerebrovascular diseases (CVD) [2,3]. In 2017, the number of patients with CVD reached 485 million worldwide, which resulted in 17.8 million deaths and placed a heavy burden on the global medical system and economy [4]. Previous studies have recommended weight loss as one of the primary measures for preventing and treating hypertension, diabetes, and CVD in overweight and obese people $[5,6]$.

Studies have shown that in overweight and obese patients with hypertension, sustained weight loss results in significant reductions in blood pressure in a dose-response manner, and improves blood lipid parameters and blood glucose [7]. However, the effects of weight loss on cardiovascular outcomes remain controversial $[8,9]$. Some studies suggest that repeated attempts to diet and exercise during the process of weight loss result in higher $\mathrm{BMI}$ variability, which increases the risk of CVD [7]. The Framingham study was the first to show that the risk of CVD was significantly increased in subjects with higher body weight variability compared with those with low body weight variability [10]. This was also demonstrated in other large cohort studies of patients with CVD or diabetes [11-13]. However, these studies were primarily carried out in Europe, the USA, Japan, and South Korea. Furthermore, most of the studies focused exclusively on the level of BMI variation and ignored the direction of weight change. To our knowledge, no studies have explored the relationship between BMI variability, weight change slope, and risk of cardiovascular outcomes in hypertension.

Therefore, based on data from the Kailuan study (registration No.: CHiCTR-TNC-11001489), we conducted a prospective cohort study to investigate the relationship between BMI variability, weight change slope, and risk of cardiovascular outcomes in hypertensive patients in north China.

\section{Subjects and Methods}

\section{Study Participants}

Between 2006 and 2007, medical staff at the Kailuan General Hospital and its 10 affiliated hospitals conducted the first of three physical examinations of current and retired staff members of the Kailuan Group, and collected relevant data. Subsequently, medical staff who participated in the first examination conducted the second (between 2008 and 2009) and third (between 2010 and 2011) physical examinations of the same population at the same locations. The study parameters, anthropometric measurements, and biochemical index measurements were the same in all three examinations.
Staff members of the Kailuan Group were included as subjects if they met the following criteria: (a) participated in three physical examinations between 2006 and 2007, 2008 and 2009, and 2010 and 2011, and (b) had hypertension [14] (defined as [1] systolic blood pressure $\geq 140 \mathrm{~mm} \mathrm{Hg}$ and/or diastolic blood pressure $\geq 90$ $\mathrm{mm} \mathrm{Hg}$, or [2] systolic blood pressure $<140 \mathrm{~mm} \mathrm{Hg}$ and DBP $<90$ $\mathrm{mm} \mathrm{Hg}$ but having had a history of hypertension that was clearly diagnosed, or taking antihypertensive drugs). Exclusion criteria were (a) having missed all height tests and any weight test, and (b) a history of myocardial infarction (MI), stroke, atrial fibrillation, or cancer before the final physical examination.

\section{Data Collection}

The study parameters, anthropometric measurements, and biochemical index measurements were as previously described by our group [15]. Height, weight, blood pressure, and other related indices were measured by trained medical staff in strict accordance with corresponding standards. For height and weight measurements, we were using a calibrated RGZ-120 scale, and weight was measured between 7:30 and 9:00 in the morning. The subjects were asked to wear light clothing, stand upright, and remove shoes and hats. Height measurement was accurate to $0.1 \mathrm{~cm}$, and weight measurement was accurate to $0.1 \mathrm{~kg}$. BMI was calculated as weight/ height $^{2}\left(\mathrm{~kg} / \mathrm{m}^{2}\right)$.

A current smoker was defined as having smoked at least 1 cigarette per day on average during the last year. A current drinker was defined as having consumed over $300 \mathrm{~mL}$ of liquor (alcohol concentration $>50 \% \mathrm{v} / \mathrm{v}$ ) per day for at least 1 year. Physical exercise was defined as having exercised over 3 times per week, with each session lasting over $30 \mathrm{~min}$. Diabetes [16] was defined as fasting blood glucose $\geq 7.0 \mathrm{mmol} / \mathrm{L}$, or fasting blood glucose $<7.0$ $\mathrm{mmol} / \mathrm{L}$ but with a clearly diagnosed history of diabetes or taking hypoglycemic drugs.

\section{Endpoints and Follow-Up}

The endpoints of the study were newly diagnosed CVD, defined as either MI or stroke (including ischemic stroke, subarachnoid hemorrhage, or intracerebral hemorrhage). Participants without MI or stroke during their follow-up were considered to have completed the study at the earlier date of either their date of death or the end of follow-up. The date of the final physical examination was taken as the starting point of follow-up. The study population was followed up from the date of the final physical examination to the earliest of the following three dates: their date of death, date of cardiovascular event, or December 31, 2017. The diagnostic criteria were based on standards of the World Health Organization $[17,18]$. The decision to hospitalize subjects, the outcomes of hospitalized subjects in hospitals affiliated with the Kailuan Group, and medical insurance claims were verified by trained medical staff. All diagnoses were confirmed by professional physicians based on hospitalization records.

\section{BMI Variability}

BMI variability was defined as intraindividual variability in the $\mathrm{BMI}$ value calculated during physical examination. Four variation indices were used: $(1)$ coefficient of variation $=(\mathrm{SD} /$ mean $\times 100 \%)$, (2) standard deviation $(\mathrm{SD})=$

$$
\sqrt{\frac{1}{n-1} \sum_{i=1}^{n}\left(x_{i}-\bar{x}\right)^{2}},
$$


Table 1. Baseline parameters of participants with hypertension in 2006

\begin{tabular}{|c|c|c|c|c|}
\hline Variable & Tertile 1 & Tertile 2 & Tertile 3 & $p$ value \\
\hline Subjects, $n$ & 6,848 & 6,912 & 6,977 & - \\
\hline Age, years & $52.58 \pm 10.80$ & $53.22 \pm 10.89$ & $53.51 \pm 11.46$ & $<0.001$ \\
\hline Male, $n(\%)$ & $5,760(84.11)$ & $5,713(82.65)$ & $5,621(80.56)$ & $<0.001$ \\
\hline Heart rate, bpm & $74.44 \pm 8.48$ & $74.72 \pm 8.50$ & $74.73 \pm 8.39$ & 0.082 \\
\hline SBP, mm Hg & $141.63 \pm 15.17$ & $142.35 \pm 15.20$ & $142.89 \pm 15.00$ & $<0.001$ \\
\hline $\mathrm{DBP}, \mathrm{mm} \mathrm{Hg}$ & $90.04 \pm 8.53$ & $89.95 \pm 8.54$ & $90.08 \pm 8.41$ & 0.067 \\
\hline $\mathrm{mBMI}, \mathrm{kg} / \mathrm{m}^{2}$ & $25.56 \pm 3.00$ & $25.74 \pm 3.04$ & $26.23 \pm 3.15$ & $<0.001$ \\
\hline Triglyceride, $\mathrm{mmol} / \mathrm{L}$ & $1.50(1.11-2.14)$ & $1.47(1.11-2.16)$ & $1.49(1.12-2.17)$ & 0.638 \\
\hline LDL-C, $\mathrm{mmol} / \mathrm{L}$ & $2.56 \pm 0.66$ & $2.55 \pm 0.66$ & $2.54 \pm 0.65$ & 0.096 \\
\hline $\mathrm{HDL}-\mathrm{C}, \mathrm{mmol} / \mathrm{L}$ & $1.53 \pm 0.31$ & $1.52 \pm 0.30$ & $1.52 \pm 0.30$ & 0.110 \\
\hline $\mathrm{eGFR}, \mathrm{mL} / \mathrm{min} \cdot 1.73 \mathrm{~m}^{2}$ & $82.96 \pm 16.89$ & $82.24 \pm 17.07$ & $80.23 \pm 18.35$ & $<0.001$ \\
\hline Uric acid, $\mu \mathrm{mol} / \mathrm{L}$ & $297.96 \pm 76.14$ & $294.07 \pm 73.80$ & $289.34 \pm 73.58$ & $<0.001$ \\
\hline Physical exercise, $n(\%)$ & $1,062(17.19)$ & $1,028(16.41)$ & $1,028(15.99)$ & 0.181 \\
\hline Current smoker, $n(\%)$ & $1,984(30.92)$ & $1,952(30.40)$ & $1,712(26.23)$ & $<0.001$ \\
\hline Current drinker, $n(\%)$ & $1,407(21.93)$ & $1,299(20.20)$ & $1,130(17.30)$ & $<0.001$ \\
\hline Diabetes, $n(\%)$ & $1,343(19.63)$ & $1,418(20.52)$ & $1,419(20.36)$ & 0.378 \\
\hline Antihypertensive drug therapy, $n(\%)$ & $1,412(20.62)$ & $1,465(21.20)$ & $1,391(19.94)$ & $<0.001$ \\
\hline
\end{tabular}

Continuous variables are described by mean $\pm \mathrm{SD}$ (normal distribution)/median (quartile, abnormal distribution); categorical variables are presented as $n$ (\%). Tertile 1: BMI_ARV $\leq 0.86$; tertile 2: $0.86<$ BMI_ARV $\leq 1.60$; tertile 3: BMI_ARV $>1.60$. SBP, systolic blood pressure; DBP, diastolic blood pressure; FBG, fasting blood glucose; mBMI, mean body mass index; LDL-C, low-density lipoprotein cholesterol; HDL-C, high-density lipoprotein cholesterol; eGFR, estimated glomerular filtration rate; hs-CRP, high-sensitivity C-reactive protein.

(3) variation independent of the mean (VIM), and (4) average real variability $(\mathrm{ARV})$. VIM $=\mathrm{SD}$ divided by the mean to the power $x$. Power $x$ was modeled as $\mathrm{SD}=k \times$ mean $^{x}$ and was derived from fitting curves by nonlinear regression analysis as implemented in the PROC NLIN procedure of the SAS package $[19,20]$. ARV is the average of the absolute differences between consecutive values and was calculated using the following formula, where $N$ denotes the number of measurements of the metabolic parameters [21]. High variability was defined as the highest tertile (tertile 3 ) of variability, and low variability was defined as the lowest tertile (tertile 1) of variability:

$$
A R V=\frac{1}{N-1} \sum_{K-1}^{N-1} \mid \text { Value }_{K+1}-\text { Value }_{k} \mid .
$$

Regarding weight change slope, weights constituted the set of body weight data obtained from physical examinations over approximately 2 years. The weights were regressed on the corresponding year of physical examination to obtain year-weight regression lines. The regression lines were constructed based on three data points corresponding to weight. The slopes of these regression lines represented the overall trend in weight change. Therefore, in the present study, slopes of weight change were used as the index of long-term weight change. A weight change slope $>0$ represented weight gain over the course of the three physical ex- aminations, while $\leq 0$ represented weight loss over the course of the three physical examinations.

\section{Statistical Analysis}

According to the tertile of BMI variability (BMI_ARV), the subjects were divided into three groups: tertile 1 with BMI_ARV $\leq 0.86$; tertile 2 with $0.86<$ BMI_ARV $\leq 1.60$; and tertile 3 with BMI_ARV $>1.60$. The baseline parameters were compared among participants in each tertile group. Continuous variables are presented as mean $\pm \mathrm{SD}( \pm s)$ and median (quartile) for normally distributed and nonnormally distributed data, respectively. Categorical variables are presented as numerical values (percentages). Continuous variables were compared using the Student $t$ test and the nonparametric test for normally distributed and nonnormally distributed data, respectively, while categorical variables were compared using the $\chi^{2}$ test.

The cumulative incidence of primary outcomes in each tertile group was calculated using the Kaplan-Meier method, and was compared with the log-rank test. Cox proportional-hazards models were used to assess the risk of CVD. $p$ values and hazard ratios (HRs) with 95\% confidence intervals (CIs) are shown. All $p$ values were calculated from two-tailed tests of statistical significance. $p<$ 0.05 was considered statistically significant. All statistical analyses were performed using SPSS version 13.0 and SAS version 9.4. 
Table 2. Hazard ratios and $95 \%$ confidence intervals of CVD

\begin{tabular}{|c|c|c|c|c|}
\hline & Events, $n$ & $\begin{array}{l}\text { Per } 1,000 \\
\text { person-years }\end{array}$ & Model 1 & Model 2 \\
\hline \multicolumn{5}{|l|}{ CVD } \\
\hline Tertile 1 & 386 & 8.44 & 1 & 1 \\
\hline Tertile 2 & 464 & 10.14 & $1.20(1.05-1.38)$ & $1.15(1.00-1.33)$ \\
\hline $\begin{array}{l}\text { Tertile } 3 \\
p \text { value for trend }\end{array}$ & 502 & 10.96 & $\begin{array}{l}1.26(1.10-1.44) \\
<0.001\end{array}$ & $\begin{array}{l}1.21(1.05-1.39) \\
0.008\end{array}$ \\
\hline \multicolumn{5}{|l|}{ Stroke } \\
\hline Tertile 1 & 311 & 6.76 & 1 & 1 \\
\hline Tertile 2 & 384 & 8.35 & $1.20(1.07-1.40)$ & $1.18(1.03-1.35)$ \\
\hline $\begin{array}{l}\text { Tertile } 3 \\
p \text { value for trend }\end{array}$ & 408 & 8.84 & $\begin{array}{l}1.26(1.09-1.46) \\
0.003\end{array}$ & $\begin{array}{l}1.21(1.04-1.38) \\
0.019\end{array}$ \\
\hline \multicolumn{5}{|l|}{ MI } \\
\hline Tertile 1 & 82 & 1.76 & 1 & 1 \\
\hline Tertile 2 & 83 & 1.77 & $0.98(0.73-1.34)$ & $0.91(0.66-1.26)$ \\
\hline $\begin{array}{l}\text { Tertile } 3 \\
p \text { value for trend }\end{array}$ & 104 & 2.22 & $\begin{array}{l}1.23(0.92-1.65) \\
0.148\end{array}$ & $\begin{array}{l}1.20(0.88-1.62) \\
0.223\end{array}$ \\
\hline
\end{tabular}

Model 1 was adjusted for age and sex. Model 2 was further adjusted for heart rate, mean body mass index, triglyceride, low-density lipoprotein cholesterol, high-density lipoprotein cholesterol, estimated glomerular filtration rate, uric acid, high-sensitivity C-reactive protein, weight change slope, physical exercise, smoking status, alcohol consumption, and diabetes. CVD, cardiovascular and cerebrovascular diseases; MI, myocardial infarction.

The accuracy of the results may have been affected by antihypertensive drug therapy, patients with diabetes, and participants with endpoints occurring within $\leq 1$ year of follow-up. Therefore, subjects who had taken antihypertensive drugs, had diabetes, and with newly diagnosed CVD within 1 year were excluded from the sensitivity analysis. Cox proportional-hazards models were also used to assess the risk of CVD in the sensitivity analysis. $p$ values were calculated from two-tailed tests of statistical significance and were considered statistically significant when $p<0.05$.

\section{Results}

\section{Baseline Parameters}

A total of 24,255 subjects with hypertension participated in three physical examinations between 2006 and 2007, 2008 and 2009, and 2010 and 2011. A total of 1,782 participants with missing data on height and weight were excluded. There were a total of 1,353 participants with a history of MI or stroke, 136 with a history of atrial fibrillation, and 247 with a history of cancer before the final physical examination. The remaining 20,737 subjects were included in the statistical analyses.

Among the 20,737 subjects, 17,094 (82.43\%) were male and 3,643 (17.57\%) were female, with an average age of $53.11 \pm 11.06$ years. The average BMI_ARV was
$1.52 \pm 1.32 \mathrm{~kg} / \mathrm{m}^{2}$. The subjects were divided into three groups according to BMI_ARV tertile, as described above. Compared with the lowest-tertile group, the subjects in tertiles 2 and 3 had significantly higher age, heart rate, mean BMI, and high-sensitivity C-reactive protein levels. Additionally, the estimated glomerular filtration rate and uric acid value, as well as the percentages of current smokers and current drinkers, were statistically higher in tertile 1 than in tertiles 2 and 3 ( $p<$ 0.05; Table 1).

\section{Cumulative Incidence of Cardiovascular Outcomes}

During the average follow-up period of 6.62 years, there were 1,352 cases of CVD, including 269 cases of MI and 1,103 cases of stroke.

The 7-year cumulative incidence of CVD in tertiles 1 , 2 , and 3 was $5.83 \%, 7.23 \%$, and $7.53 \%$, respectively. That of stroke was $4.75 \%, 6.01 \%$, and $6.13 \%$, respectively, while that of MI was $1.20 \%, 1.28 \%$, and $1.56 \%$, respectively. A log-rank test showed there were significant differences in cumulative incidence rates of CVD $\left(\chi^{2}=14.209, p<\right.$ $0.001)$ and stroke $\left(\chi^{2}=12.951, p=0.002\right)$, but not in the cumulative incidence of MI $\left(\chi^{2}=3.380, p=0.185\right)$, between the three groups $(p<0.05)$. 
Table 3. Baseline parameters of the participants with different weight change slopes in 2006

\begin{tabular}{lccc}
\hline Variable & $\begin{array}{l}\text { Weight change } \\
\text { slope } \leq 0\end{array}$ & $\begin{array}{l}\text { Weight change } \\
\text { slope }>0\end{array}$ & $p$ value \\
\hline Subjects, $n$ & 11,047 & 9,690 & - \\
mBMI, kg/m & $25.87 \pm 3.05$ & $25.82 \pm 3.12$ & 0.279 \\
BMI_ARV, $\mathrm{kg} / \mathrm{m}^{2}$ & $1.21(0.75-1.95)$ & $1.17(0.70-1.84)$ & $<0.001$ \\
BMI in 2006, kg/m & $26.78 \pm 3.31$ & $25.15 \pm 3.20$ & 0.302 \\
BMI in 2008, $\mathrm{kg} / \mathrm{m}^{2}$ & $25.74 \pm 3.32$ & $25.59 \pm 3.35$ & 0.9121 \\
BMI in 2010, $\mathrm{kg} / \mathrm{m}^{2}$ & $25.07 \pm 3.13$ & $26.72 \pm 3.32$ & 0.277 \\
\hline
\end{tabular}

Continuous variables are described by mean \pm SD (normal distribution)/median (quartile, abnormal distribution). mBMI, mean body mass index.

Table 4. Hazard ratios (HRs) and 95\% confidence interval of CVD with different weight change slope directions

\begin{tabular}{llll}
\hline & CVD & Stroke & MI \\
\hline Weight change slope $>0(n=9,690)$ & & & \\
$\quad$ Tertile 1 & 1 & 1 & 1 \\
$\quad$ Tertile 2 & $1.17(0.95-1.44)$ & $1.22(0.97-1.53)$ & $0.97(0.59-1.59)$ \\
$\quad$ Tertile 3 & $1.38(1.11-1.72)$ & $1.33(1.04-1.70)$ & $1.71(1.06-2.75)$ \\
Weight change slope $\leq 0(n=11,047)$ & & \\
$\quad$ Tertile 1 & 1 & 1 & 1 \\
Tertile 2 & $1.15(0.94-1.40)$ & $1.19(0.96-1.48)$ & $0.92(0.59-1.43)$ \\
Tertile 3 & $1.11(0.89-1.37)$ & $1.11(0.88-1.41)$ & $0.98(0.61-1.58)$ \\
\hline
\end{tabular}

Adjusted for age, sex, heart rate, mean body mass index, triglyceride, low-density lipoprotein cholesterol, high-density lipoprotein cholesterol, estimated glomerular filtration rate, uric acid, high-sensitivity C-reactive protein, weight change slope, physical exercise, smoking status, alcohol consumption, and diabetes. CVD, cardiovascular and cerebrovascular diseases; MI, myocardial infarction.

\section{BMI Variability and Outcomes}

Table 2 shows the correlation between BMI variability and CVD according to Cox proportional-hazards regression analysis. An incrementally higher risk of CVD, MI, and stroke was observed for the higher tertiles compared with the lowest-tertile group. The associations between BMI variability and outcomes were confirmed after adjusting for baseline age, sex, heart rate, mean BMI, triglyceride, low-density lipoprotein cholesterol, high-density lipoprotein cholesterol, estimated glomerular filtration rate, uric acid, high-sensitivity C-reactive protein, weight change slope, physical exercise, smoking status, alcohol consumption, diabetes, and antihypertensive drug therapy. Compared with the lowest tertile, the risk of CVD increased by $21 \%$ (HR 1.21; 95\% CI 1.05-1.39), while the risk of MI increased by $20 \%$ (HR 1.20; 95\% CI 0.88-1.62), and that of stroke increased by $21 \%$ (HR $1.21 ; 95 \%$ CI 1.04-1.41).
The total population was further divided into two groups according to the direction of the weight change slope: $\leq 0$ or $>0$. Among the 20,737 participants, 11,047 (53.27\%) experienced weight gain over the course of the three physical examinations (weight change slope $>0$ ), while 9,690 (46.73\%) experienced weight loss (weight change slope $\leq 0)$. BMI_ARV was $1.21(0.75-1.95)$ and the mean BMI was $25.87 \pm 3.05$ among the subjects with a weight change slope $\leq 0$. BMI_ARV was $1.17(0.70-$ 1.84 ) and the mean BMI was $25.82 \pm 3.12$ among the subjects with a weight change slope $>0$ (Table 3 ).

An association of BMI variability with risk of CVD was present in the weight gain group. Additionally, higher BMI variability was associated with an increased risk of CVD, stroke, and MI in the weight gain group, while no significant differences were observed across the BMI_ARV tertiles in the weight loss group. In the "weight change slope $>0$ " group, the adjusted HRs (95\% CI) values for CVD, 
Table 5. Hazard ratios and $95 \%$ confidence intervals of CVD

\begin{tabular}{lccc}
\hline \multicolumn{1}{l}{ Subjects } & CVD & Stroke & MI \\
\hline Excluding 4,268 subjects with antihypertensive drug therapy & & \\
Tertile 1 & 1 & 1 & 1 \\
Tertile 2 & $1.22(1.04-1.45)$ & $1.27(1.06-1.53)$ & $0.65(0.62-1.35)$ \\
Tertile 3 & $1.27(1.07-1.50)$ & $1.30(1.08-1.56)$ & $1.29(0.90-1.86)$ \\
Excluding 4,180 subjects with diabetes & & \\
Tertile 1 & 1 & 1 & 1 \\
Tertile 2 & $1.13(0.96-1.30)$ & $1.16(0.99-1.38)$ & $0.85(0.60-1.28)$ \\
Tertile 3 & $1.17(1.01-1.35)$ & $1.20(1.04-1.43)$ & $1.11(0.83-1.64)$ \\
Excluding 273 subjects newly diagnosed with CVD within 1 year & 1 \\
Tertile 1 & 1 & 1 & \\
Tertile 2 & $1.18(1.01-1.36)$ & $1.20(1.02-1.42)$ & $0.92(0.65-1.31)$ \\
Tertile 3 & $1.20(1.03-1.39)$ & $1.23(1.05-1.45)$ & $1.18(0.85-1.65)$ \\
\hline
\end{tabular}

Adjusted for age, sex, heart rate, mean BMI, triglyceride, low-density lipoprotein cholesterol, high-density lipoprotein cholesterol, estimated glomerular filtration rate, uric acid, high-sensitivity C-reactive protein, weight change slope, physical exercise, smoking status, alcohol consumption, diabetes, and antihypertensive drug therapy (nonadjusted after exclusion). CVD, cardiovascular and cerebrovascular diseases; MI, myocardial infarction.

stroke, and MI in tertile 3 were 1.38 (1.11-1.72), 1.33 (1.041.70 ), and 1.71 (1.06-2.75), respectively, compared with tertile 1 . In the "weight change slope $\leq 0$ " group, the adjusted HRs (95\% CI) values for CVD, stroke, and MI in tertile 3 were $1.11(0.89-1.37), 1.11(0.88-1.41)$, and 0.98 (0.61-1.58), respectively, compared with tertile 1 (Table 4 ).

\section{Sensitivity Analysis}

A sensitivity analysis was conducted to exclude subjects who participated in only two physical examinations, those with diabetes, and those with newly diagnosed CVD within 1 year. The results showed that, in accordance with the previous statistical results, higher variability in BMI led to a higher risk of CVD (Table 5).

\section{Discussion}

To our knowledge, this is the first study to explore the relationship between BMI variability and CVD in patients with hypertension. Our results showed that in hypertensive subjects, higher BMI variability was associated with increased risk of CVD and stroke. This increased risk persisted after adjustment for BMI and traditional cardiovascular risk factors. However, we found no significant association between BMI variability and MI. In addition, the correlation between BMI variability and CVD existed only in subjects with weight gain, not in those with weight loss.

Among subjects with hypertension, higher BMI variability was associated with higher risk of CVD, indepen- dent of traditional cardiovascular risk factors. Our study showed that after adjustment for confounding factors including mean BMI, weight change slope, and traditional cardiovascular risk factors, compared with tertile 1 , the risk of CVD increased by $15 \%$ in tertile 2 and by $21 \%$ in tertile 3 , and the risk of stroke increased by $18 \%$ in tertile 2 and by $21 \%$ in tertile 3 . Our findings are consistent with those of previous studies. According to the 32-year followup of 3,171 subjects from the general population from the Framingham study, those with higher BMI variability have an increased risk of CVD compared with those with low BMI variability (men: 1.93 [1.35-2.77]; women: 1.55 [1.09-2.21]) [10]. Bangalore et al. [11, 12] found that each increase of $1 \mathrm{SD}$ in BMI variability in patients with diabetes or coronary artery disease increased the risk of CVD by 1.08 and 1.04, respectively. However, we found no significant association between BMI variability and MI. Compared with the above studies, the incidence of MI in our study was significantly lower. These discrepancies may be attributed to differences in the populations studied and racial disparities. Previous studies showed that the incidence of MI in Chinese subjects was lower than in Caucasians [22,23]. Additionally, because of differences in the methods used for assessment, and the absence of consensus on a standard definition of weight fluctuation, it was difficult to make cross-study comparisons, thereby leading to challenges in drawing definitive conclusions [24].

The relationship between BMI variability and CVD in patients with hypertension was related to both the level and the direction of variation of changes in weight. In the 
"weight change slope $>0$ " group, the adjusted HR (95\% CI) for incident CVD was $1.38(1.11-1.72)$ in the highest tertile compared with tertile 1 . Weight gain was associated with higher risk of CVD $[25,26]$. In addition, we found that increased BMI variability during the process of weight gain was a risk factor for incident CVD. However, we did not observe a significant association between BMI variability and any cardiovascular or cerebrovascular event in subjects with weight loss (Table 4). More specifically, according to our results, increased BMI variability during the process of weight loss did not increase the risk of CVD. Weight loss strategies for preventing and treating obesityrelated diseases are strongly supported by this important finding. Previous studies have shown that in overweight and obese patients with hypertension, sustained weight loss reduces blood pressure in a dose-response manner, and improves blood lipid parameters, blood glucose, and insulin resistance [7], which can effectively modify the related risk factors for CVD. However, our subjects with weight loss had had a higher BMI at baseline (Table 3), which has the potential to adversely affect CVD $[2,3]$. Further study is required to follow up the subjects with weight loss in order to assess their cardiovascular outcomes.

The mechanisms underlying the adverse effects of BMI variability on CVD remain incompletely understood. However, plausible explanations have been suggested in several studies. According to a mouse study, weight cycling induced greater adipose tissue inflammation and insulin resistance than a consistent obese state [27]. A positive association was found between fasting insulin concentration and history of weight fluctuations in a cross-sectional analysis of 1,932 middle-aged Japanese men [28]. Individuals with larger weight fluctuations had significantly higher fasting insulin $(r=0.125, p<0.001)$. Insulin resistance is a core pathological feature of CVD [29]. Furthermore, some studies showed that traditional cardiovascular risk factors, such as blood pressure, heart rate, blood glucose, and blood lipids, are also significantly associated with high BMI variability [30]. This pathological mechanism also occurs in weight gain. Several studies showed that weight gain leads to insulin resistance, adipocyte inflammation, and abnormal metabolism, resulting in increased oxidative stress and endothelial dysfunction, which ultimately promote the occurrence of atherosclerosis [31-34].

This study has several limitations. First, we were unaware whether weight changes were intentional or unintentional. Intentional weight loss may be associated with a reduction in cardiovascular events, whereas unintentional weight loss may be associated with an increased rate of events [35]. However, we excluded participants diagnosed with CVD or cancer during the measurement of weight changes, as well as subjects with diabetes in the sensitivity analysis, thereby minimizing the interference of diseases. Second, this was an observational study, and it was therefore impossible to unravel cause-effect relationships. To minimize the potential effects of reverse causality, we excluded subjects newly diagnosed with CVD within 1 year and showed consistent results. Third, in the present study, only three BMI measurements per participant were available, which was a considerable limitation. Finally, this study was conducted in a Chinese population and most participants were male. The conclusions may therefore not apply to other racial or ethnic groups. Despite these limitations, our study provides a very novel and informative opinion on the relationship between BMI variability and CVD in a large hypertensive population.

\section{Conclusion}

BMI variability was an independent risk factor for CVD in this hypertensive population. In addition, we found that BMI variability was associated with a higher risk of CVD with positive weight change, not with negative weight change.

\section{Statement of Ethics}

The present study was approved by the Ethics Committee of Kailuan General Hospital in accordance with the Declaration of Helsinki, and each participant signed the informed consent forms.

\section{Conflict of Interest Statement}

The authors have no conflicts of interest to declare.

\section{Funding Sources}

This work has been supported by the National Natural Science Foundation of China (No. 81870312).

\section{Author Contributions}

Y.C. conceived the study idea and designed the study together with S.W., Zefeng Cai, and W.W.; W.W., Zekai Chen, W.F., W.L., G.C., and Zhichao Chen analyzed and interpreted the data; Zefeng Cai drafted the manuscript, which was critically revised by S.W. and Y.C.; S.W. and Y.C. approved the manuscript and are the guarantors of this work and take responsibility for the integrity of the data and the accuracy of the data analyses. 


\section{References}

1 Afshin A, Forouzanfar MH, Reitsma MB, Sur P, Estep K, Lee A, et al.; GBD 2015 Obesity Collaborators. Health Effects of Overweight and Obesity in 195 Countries over 25 Years. N Engl J Med. 2017 Jul;377(1):13-27.

2 Bray GA. Medical consequences of obesity. J Clin Endocrinol Metab. 2004 Jun;89(6):25839.

3 Haslam DW, James WP. Obesity. Lancet. 2005 Oct;366(9492):1197-209.

4 James SL, Abate D, Abate KH, Abay SM, Abbafati C, Abbasi N, et al.; GBD 2017 Disease and Injury Incidence and Prevalence Collaborators. Global, regional, and national incidence, prevalence, and years lived with disability for 354 diseases and injuries for 195 countries and territories, 1990-2017: a systematic analysis for the Global Burden of Disease Study 2017. Lancet. 2018 Nov;392(10159):1789-858.

5 Ryan D, Heaner M. Guidelines (2013) for managing overweight and obesity in adults. Preface to the full report. Obesity (Silver Spring). 2014 Jul;22(Suppl 2):S1-3.

6 Jebb SA, Ahern AL, Olson AD, Aston LM, Holzapfel C, Stoll J, et al. Primary care referral to a commercial provider for weight loss treatment versus standard care: a randomised controlled trial. Lancet. 2011 Oct;378(9801): 1485-92.

7 Klein S, Burke LE, Bray GA, Blair S, Allison DB, Pi-Sunyer X, et al.; American Heart Association Council on Nutrition, Physical Activity, and Metabolism. Clinical implications of obesity with specific focus on cardiovascular disease: a statement for professionals from the American Heart Association Council on Nutrition, Physical Activity, and Metabolism: endorsed by the American College of Cardiology Foundation. Circulation. 2004 Nov;110(18):2952-67.

8 Yang D, Fontaine KR, Wang C, Allison DB. Weight loss causes increased mortality: cons. Obes Rev. 2003 Feb;4(1):9-16.

9 Danaei G, Robins JM, Young JG, Hu FB, Manson JE, Hernán MA. Weight Loss and Coronary Heart Disease: Sensitivity Analysis for Unmeasured Confounding by Undiagnosed Disease. Epidemiology.2016 Mar;27(2): 302-10.

10 Lissner L, Odell PM, D’Agostino RB, Stokes J 3rd, Kreger BE, Belanger AJ, et al. Variability of body weight and health outcomes in the Framingham population. N Engl J Med. 1991 Jun;324(26):1839-44.

11 Bangalore S, Fayyad R, Laskey R, DeMicco DA, Messerli FH, Waters DD. Body-Weight Fluctuations and Outcomes in Coronary Disease. N Engl J Med. 2017 Apr;376(14):133240.

12 Bangalore S, Fayyad R, DeMicco DA, Colhoun HM, Waters DD. Body Weight Variability and Cardiovascular Outcomes in $\mathrm{Pa}$ tients with Type 2 Diabetes Mellitus. Circ Cardiovasc Qual Outcomes. 2018 Nov;11(11): e004724.
13 Yeboah P, Hsu FC, Bertoni AG, Yeboah J. Body Mass Index, Change in Weight, Body Weight Variability and Outcomes in Type 2 Diabetes Mellitus (from the ACCORD Trial). Am J Cardiol. 2019 Feb;123(4):576-81.

14 Joint Committee for Guideline Revision. 2018 Chinese Guidelines for Prevention and Treatment of Hypertension - a report of the Revision Committee of Chinese Guidelines for Prevention and Treatment of Hypertension. J Geriatr Cardiol. 2019 Mar;16(3):182-241.

15 Wu S, Huang Z, Yang X, Zhou Y, Wang A, Chen L, et al. Prevalence of ideal cardiovascular health and its relationship with the 4-year cardiovascular events in a northern Chinese industrial city. Circ Cardiovasc Qual Outcomes. 2012 Jul;5(4):487-93.

16 National guidelines for the prevention and control of diabetes in primary care (2018). Zhonghua Nei Ke Za Zhi. 2018 Dec 1;57(12): 885-93 Chinese.

17 Rose GA. Cardiovascular survey methods. WHO Monograph Series No. 58. Geneva, Switzerland: World Health Organization; 1982.

18 Stroke - 1989. Recommendations on stroke prevention, diagnosis, and therapy. Report of the WHO Task Force on Stroke and Other Cerebrovascular Disorders. Stroke. 1989 Oct; 20(10):1407-31.

19 Asayama K, Kikuya M, Schutte R, Thijs L, Hosaka M, Satoh M, et al. Home blood pressure variability as cardiovascular risk factor in the population of Ohasama. Hypertension. 2013 Jan;61(1):61-9.

20 Fukuda K, Kai H, Kamouchi M, Hata J, Ago $\mathrm{T}$, Nakane $\mathrm{H}$, et al.; FSR Investigators; steering committee of the Fukuoka Stroke Registry included. Day-by-Day Blood Pressure Variability and Functional Outcome after Acute Ischemic Stroke: Fukuoka Stroke Registry. Stroke. 2015 Jul;46(7):1832-9.

21 Mena L, Pintos S, Queipo NV, Aizpúrua JA, Maestre G, Sulbarán T. A reliable index for the prognostic significance of blood pressure variability. J Hypertens. 2005 Mar;23(3):50511.

22 Tunstall-Pedoe H, Kuulasmaa K, Mähönen M, Tolonen H, Ruokokoski E, Amouyel P. Contribution of trends in survival and coronary-event rates to changes in coronary heart disease mortality: 10-year results from 37 WHO MONICA project populations. Monitoring trends and determinants in cardiovascular disease. Lancet. 1999 May;353(9164):1547-57.

23 Yusuf S, Reddy S, Ounpuu S, Anand S. Global burden of cardiovascular diseases: part I: general considerations, the epidemiologic transition, risk factors, and impact of urbanization. Circulation. 2001 Nov;104(22):274653.

24 Mehta T, Smith DL Jr, Muhammad J, Casazza $\mathrm{K}$. Impact of weight cycling on risk of morbidity and mortality. Obes Rev. 2014 Nov; 15(11):870-81.
25 de Mutsert R, Sun Q, Willett WC, Hu FB, van Dam RM. Overweight in early adulthood, adult weight change, and risk of type 2 diabetes, cardiovascular diseases, and certain cancers in men: a cohort study. Am J Epidemiol. 2014 Jun;179(11):1353-65.

26 Wannamethee SG, Shaper AG, Walker M. Overweight and obesity and weight change in middle aged men: impact on cardiovascular disease and diabetes. J Epidemiol Community Health. 2005 Feb;59(2):134-9.

27 Fuster JJ, Ouchi N, Gokce N, Walsh K. Obesity-Induced Changes in Adipose Tissue Microenvironment and Their Impact on Cardiovascular Disease. Circ Res. 2016 May; 118(11):1786-807.

28 Yatsuya H, Tamakoshi K, Yoshida T, Hori Y, Zhang H, Ishikawa M, et al. Association between weight fluctuation and fasting insulin concentration in Japanese men. Int J Obes Relat Metab Disord. 2003 Apr;27(4):478-83.

29 Rader DJ. Effect of insulin resistance, dyslipidemia, and intra-abdominal adiposity on the development of cardiovascular disease and diabetes mellitus. Am J Med. 2007;120(3 Suppl 1):S12-S8.

30 Montani JP, Schutz Y, Dulloo AG. Dieting and weight cycling as risk factors for cardiometabolic diseases: who is really at risk? Obes Rev. 2015 Feb;16(Suppl 1):7-18.

31 Erdmann J, Kallabis B, Oppel U, Sypchenko O, Wagenpfeil S, Schusdziarra V. Development of hyperinsulinemia and insulin resistance during the early stage of weight gain. Am J Physiol Endocrinol Metab. 2008 Mar; 294(3):E568-75.

32 Poirier P, Giles TD, Bray GA, Hong Y, Stern JS, Pi-Sunyer FX, et al.; American Heart Association; Obesity Committee of the Council on Nutrition, Physical Activity, and Metabolism. Obesity and cardiovascular disease: pathophysiology, evaluation, and effect of weight loss: an update of the 1997 American Heart Association Scientific Statement on Obesity and Heart Disease from the Obesity Committee of the Council on Nutrition, Physical Activity, and Metabolism. Circulation. 2006 Feb;113(6):898-918.

33 Van Gaal LF, Mertens IL, De Block CE. Mechanisms linking obesity with cardiovascular disease. Nature. 2006 Dec;444(7121):875-80.

34 Lavie CJ, Milani RV, Ventura HO. Obesity and cardiovascular disease: risk factor, paradox, and impact of weight loss. J Am Coll Cardiol. 2009 May;53(21):1925-32.

35 Pack QR, Rodriguez-Escudero JP, Thomas RJ, Ades PA, West CP, Somers VK, et al. The prognostic importance of weight loss in coronary artery disease: a systematic review and meta-analysis. Mayo Clin Proc. 2014 Oct; 89(10):1368-77. 